\title{
Long-Term Safety and Efficacy Data of a Plasma- Derived Factor VIII Concentrate with von Willebrand Factor for Treatment of Patients with Hemophilia A Covering 18 Years
}

\author{
Sabine Friederike Karolin Kittler ${ }^{1}$ Wolfgang Miesbach ${ }^{2}$ Artur Bauhofer ${ }^{1}$ Thomas Becker ${ }^{1}$ \\ Jörg Schüttrumpf ${ }^{1}$ Patrick Dubovy ${ }^{1}$ László Nemes ${ }^{3}$ Heinrich Richter ${ }^{4}$ Christoph Königs ${ }^{5}$
}

\footnotetext{
${ }^{1}$ Biotest AG, Dreieich, Germany

2 Hemophilia Center, Institute of Transfusion Medicine, University Hospital Frankfurt, Frankfurt/Main, Germany

${ }^{3}$ National Hemophilia Center and Hemostasis Department, Medical Center, Hungarian Defence Forces, Budapest, Hungary

${ }^{4}$ Coagulation Center Muenster, Muenster, Germany

${ }^{5}$ Department of Pediatrics, Hemophilia Center, Goethe University,

University Hospital Frankfurt, Frankfurt/Main, Germany
}

Address for correspondence Sabine Friederike Karolin Kittler, Biotest AG, Landsteiner Street 5, 63303 Dreieich, Germany (e-mail: sabine.kittler@biotest.com).

\section{Abstract \\ Keywords \\ - hemophilia A \\ - plasma-derived factor VIII \\ - FVIII inhibitor \\ - noninterventional study}

Zusammenfassung
We describe the results of the (to our knowledge) longest long-term noninterventional study so far performed to obtain real-life data on the treatment of hemophilia $A$ patients with a single plasma-derived FVIII concentrate containing von Willebrand factor (pdFVIII; Haemoctin/Faktor VIII SDH Intersero). A total of 198 patients (146 in Germany and 52 in Hungary), of whom 160 had severe and 38 nonsevere hemophilia A, representing all age groups ( $0-88$ years; mean $\sim 25$ years at inclusion) were analyzed during prophylactic or on-demand treatment over 18 years (overall 1,418 patientyears; mean $>7$ years). pdFVIII was very effective and well tolerated. The mean annual bleeding rate, including spontaneous and traumatic bleeds, was considerably lower for patients treated prophylactically (mean 5.4; median 3.1) than for patients treated on demand (mean 26.1; median 21.9). Inhibitors were found in 13\% (3/23) and high-titer inhibitors in $4 \%(1 / 23)$ of previously untreated patients with severe hemophilia $A$. Four previously treated patients with severe hemophilia A developed inhibitors, thereof three high-titer inhibitors (3.3 and 2.5 high-titer inhibitors in 1,000 patient-years). No unexpected adverse effect on the health of the patients, no pdFVIII-related thrombosis, thromboembolic event, or hypersensitivity reaction, and no suspected viral transmission related to pdFVIII were documented.

Wir berichten über die Ergebnisse der unseres Wissens längsten nicht-interventionellen Langzeitstudie mit einem von-Willebrand-Faktor-haltigem humanen FVIII-Konzentrat

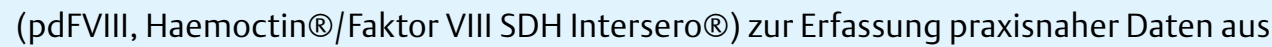
der alltäglichen Therapie von Patienten mit einer Hämophilie A. 198 Patienten (146 in Deutschland und 52 in Ungarn) aller Altersgruppen (0-88 Jahre; durchschnittlich 25 received

February 26, 2019

accepted after revision

August 21, 2019 (c) 2019 Georg Thieme Verlag KG Stuttgart · New York
DOI https://doi.org/ 10.1055/s-0039-1698810. ISSN 0720-9355. 
Schlüsselwörter

- Hämophilie A

- plasmatischer Faktor VIII

- FVIII Inhibitor

- nichtinterventionelle Studie
Jahre alt beim Einschluss), 160 davon mit schwerer und 38 mit nicht schwerer Hämophilie A, wurden im Rahmen ihrer prophylaktischen oder Bedarfstherapie über 18 Jahre analysiert (insgesamt 1418 Patientenjahre; durchschnittlich $>7$ Jahre). Der pdFVIII erwies sich als sehr wirksam und verträglich. Die durchschnittliche jährliche Blutungsrate (spontane und traumatische Blutungen) war deutlich geringer in Patienten, die prophylaktisch (Mittelwert 5,4; Median 3,1) anstatt bei Bedarf (Mittelwert 26,1; Median 21,9) mit pdFVIII behandelt wurden. Inhibitoren wurden in 13\% (3/23) und hochtitrige in $4 \%(1 / 23)$ der zuvor unbehandelten Patienten mit schwerer Hämophilie A dokumentiert. Vier der vorbehandelten Patienten mit schwerer Hämophilie A entwickelten Inhibitoren, 3 davon hochtitrige (3.3 Inhibitoren und 2.5 hochtitrige pro 1000 Patientenjahren). Während der Langzeittherapie mit pdFVIII wurde kein unerwünschter Einfluss auf den allgemeinen Gesundheitszustand der Patienten festgestellt. Es trat keine thromboembolische Reaktion, keine Überempfindlichkeitsreaktion, und keine Virusübertragung im kausalen Zusammenhang mit pdFVIII auf.

\section{Introduction}

Hemophilia $\mathrm{A}$ is a chronic disease caused by a congenital deficiency of coagulation factor VIII (FVIII) and requires lifelong hemostatic treatment. Long-term pharmacovigilance data are important to prove that a treatment is safe and efficacious in the real-life setting during long-term up to life-long therapy. Until recently, FVIII preparations were the only treatment option. New therapies including nonfactor therapeutic agents and gene therapy have been, and are becoming increasingly, available for treatment of hemophilia A. However, at least in the near future and probably for longer, (concomitant) therapy with FVIII concentrates will continue to be necessary for treatment of hemophilia $A,{ }^{1,2}$ emphasizing the continuous need for data on FVIII replacement therapy.

Development of inhibitory antibodies against FVIII is the most serious complication associated with the use of FVIII concentrates; the antibodies neutralize the infused factor, rendering patients resistant to conventional replacement treatment. $^{3}$

FVIII antibodies occur more frequently in patients with severe hemophilia A than in those with moderate or mild hemophilia A. The risk of inhibitor development in patients with severe hemophilia A ranges from approximately 27 to $45 \%{ }^{4}$ Notably, in patients with severe hemophilia $A$, inhibitors develop almost exclusively within the first 50 exposure days (EDs), whereas for patients with nonsevere disease the risk is life-long. ${ }^{4-7}$

To acquire more clinical data and to ensure consistency between the outcomes of treatment in clinical studies and in routine use, long-term postmarketing noninterventional studies (NISs) are necessary. ${ }^{8}$

This prospective observational study was initiated to collect real-life data on long-term treatment with a plasma-derived FVIII concentrate (pdFVIII; Haemoctin/Faktor VIII SDH Intersero) stabilized with von Willebrand factor $(v W F)$. Data were taken from clinical practice and routine daily treatment, and the aim of the study was to investigate the influence of the treatment on the health of hemophilia $\mathrm{A}$ patients including all age groups. Safety and effectiveness data were collected while pdFVIII was being used in the prophylactic or on-demand setting. Analysis of interim data with 109 patients was presented in 2012. ${ }^{9}$

\section{Materials and Methods}

\section{Study Treatment}

The pdFVIII concentrate administered in this study was manufactured by Biotest Pharma GmbH (Dreieich, Germany). pdFVIII is produced from human plasma in a manner that complies with the relevant European Pharmacopoeia monograph; it is provided as a powder along with a solvent for dissolution for injection. The pdFVIII molecule is present in a physiological complex with vWF, without added artificial stabilizers. The ratio of the quantity of vWF to FVIII activity (vWF:Ag/FVIII:C) in pdFVIII is approximately 0.4 , which means a significant excess of binding sites in vWF for FVIII. The manufacturing process of pdFVIII includes two virus inactivation steps using solvent/detergent (Polysorbate 80/TNBP) and a heat treatment at $100^{\circ} \mathrm{C}$. These two steps ensure high margins of safety for the FVIII preparation, particularly with respect to human immunodeficiency virus and hepatitis $\mathrm{A}, \mathrm{B}$, and $\mathrm{C}$ virus.

Patients receiving this pdFVIII were included in this combined NIS conducted by Biotest AG and Intersero $\mathrm{GmbH}$, respectively.

\section{Setting}

The observation period for each patient was planned to be at least 12 months. The studies were conducted at 34 German and 8 Hungarian hemophilia centers. Final data from the two studies were merged; they covered nearly the same observation period (May 1998 to December 2015 and January 1998 to January 2014). Observation plans and case report forms (CRFs) were highly comparable for the two studies. The studies were approved by ethics committees, and informed consent was obtained from the study patients from 2013 onwards.

\section{Study Design}

The study was a prospective, multicenter, binational, long-term NIS of the safety and efficacy of pdFVIII in hemophilia A patients. 


\section{Participants}

Patients with severe or nonsevere hemophilia A were included who were receiving treatment with pdFVIII on the basis of the recommendations in the Summary of Product Characteristics for pdFVIII. There were no specific exclusion criteria, to avoid any selection.

This final analysis includes all data acquired from January 1998 until December 2015 (inclusive). Patients were classified as previously treated patients (PTPs) or previously untreated patients (PUPs). PUPs are defined as those patients who had never been treated with clotting-factor concentrates.

\section{Variables and Data Sources}

Treatments with pdFVIII and visits were at the discretion of the physician. However, patients were required to attend for at least one annual visit at the hemophilia treatment centers. Most of the patients had three to four routine visits per year.

Variables as described below were documented in paper CRFs and are summarized in more detail in - supplementary Table 1. In addition, the doses administered of pdFVIII, bleedings, and reasons for administration were recorded in patient diaries.

\section{Data Sources and Measurement}

Data were entered from the CRFs and diaries into the clinical database at Metronomia Clinical Research GmbH (Munich, Germany). In addition, safety data for all patients were documented at the safety department at Biotest AG.

\section{Assessment of Effectiveness}

Effectiveness was analyzed by the annual bleeding rate (ABR), by assessing the expected therapeutic effect and by global assessment of effectiveness, ease of use, the patient's condition, and joint status as judged by the investigator and a global hemostatic assessment by the patient. Documented bleedings and calculations of the ABR included traumatic and spontaneous bleedings. "Bleeding" was not predefined. Documented days with bleedings in the patient diaries, bleeding episodes per month, per year, per 3- to 4-year period (1998-2002, 2003-2007, 2008-2012, and 20132015), and over the whole study period, taking into account the actual treatment, were used for analyzing the ABR.

For global assessment of effectiveness, the possible ratings were "very good" (1), "good" (2), "moderate” (3), "poor," (4) and "none" (5). For global assessment of ease of use, these were "very good" (1), "good" (2), "satisfactory" (3), "adequate," (4) and "poor" (=5).

Treatment and effectiveness data obtained from patients during immune tolerance induction (ITI) treatment were not included in the summaries of effectiveness.

The scores from global assessments by investigators and patients were analyzed as continuous variables. For each patient a mean of all ratings over the whole study was first calculated, and this was then summarized for all patients.

\section{Safety and Tolerability Assessment}

Adverse events (AEs)-including any bleedings due to suspected lack of efficacy of prophylactic treatment, aggravation of underlying or newly diagnosed diseases, and laboratory assessments of selected clinical, biochemical, and hematological variables-were documented. They were assessed (and, if clinically relevant, commented on) by the physician; any deviation from normal range, clinical relevance, severity, seriousness, and pdFVIII relationship were taken into account. In contrast to most studies, the presence of a FVIII inhibitor was already documented after the first positive result (above the normal range $\geq 0.6$ Bethesda units, BU, per $\mathrm{mL}$, depending on the center-specific sensitivity of the assay) without the need for confirmatory testing.

A global assessment of tolerability was performed by both the investigator and the patient using the possible ratings: "very good" (1), "good" (2), "moderate," (3) or "poor" (4). The same scale was used by physicians to assess the subjective conditions of the patients.

\section{Treatment Regimen}

Dosage and frequency of the pdFVIII administration were based on the Summary of Product Characteristics. pdFVIII was administered at the physician's discretion. Reasons for pdFVIII treatment were classified by the physician as "prophylaxis," "bleeding," "follow-on treatment" (on demand), or "surgery" ("surgery" as an option for treatment was not available at the start of the study, but was introduced with a CRF update in 2013); there were no study-specific definitions for the different treatment regimens, which were analyzed as documented by the investigator.

\section{Statistical Analysis}

Descriptive statistical methods were applied for final analysis. Generally, categorical variables were summarized by number of observations $(N)$, frequency count $(n)$, and percentage of patients at each level of response. Continuous variables were summarized by $N$, mean, standard deviation (SD), median, minimum, and maximum values. Data were analyzed by means of the SAS system version 9.4 (SAS Institute Inc.; Cary, North Carolina, United States).

\section{Results}

\section{Patients and Treatment}

Starting in January 1998, a total of 199 male patients were enrolled and 198 were analyzed until the end of 2015. One patient was excluded from effectiveness analysis because no treatment data were recorded. Of the remaining 198 patients, 52 were treated at Hungarian and 146 at German centers. Thirty patients were enrolled as PUPs and 168 as PTPs. A subgroup of 160 patients had severe hemophilia A (FVIII residual activity $\leq 1 \%$ ); 137 patients with severe hemophilia A were enrolled as PTPs and 23 patients as PUPs (-Table 1).

During the 18-year observation period, the mean $( \pm \mathrm{SD})$ documentation time for all patients was $7.3 \pm 5.1$ years; for patients with severe hemophilia $A$ it was $7.8 \pm 5.0$ years.

The mean number of infusions for all patients was $665.9 \pm 580.8$.

A total of 1,418 patient-years (including 1,215 patient-years in patients with severe hemophilia A) were documented. 
Table 1 Demographics-status of treatment, severity of hemophilia A, age, treatment modality at inclusion, and treatment modality at the end of study

\begin{tabular}{|c|c|c|c|c|c|c|}
\hline \multirow[t]{3}{*}{ Age at inclusion $(y)$} & \multicolumn{2}{|c|}{$\operatorname{PTP}(N=168)^{a}$} & \multicolumn{2}{|c|}{ PUP $(N=30)^{b, c}$} & \multicolumn{2}{|c|}{ All $(N=198)$} \\
\hline & $\begin{array}{l}\text { Severe } \\
(n=137)^{d}\end{array}$ & $\begin{array}{l}\text { Nonsevere } \\
(n=31)\end{array}$ & $\begin{array}{l}\text { Severe } \\
(n=23)\end{array}$ & $\begin{array}{l}\text { Nonsevere } \\
(n=7)\end{array}$ & $\begin{array}{l}\text { Severe } \\
(n=160)^{d}\end{array}$ & $\begin{array}{l}\text { Nonsevere } \\
(n=38)\end{array}$ \\
\hline & \multicolumn{2}{|l|}{$n(\%)$} & \multicolumn{2}{|l|}{$n(\%)$} & \multicolumn{2}{|l|}{$n(\%)$} \\
\hline$<1$ & $3(2.2)$ & $0(0.0)$ & $16(69.6)$ & $1(14.3)$ & $19(11.9)$ & $1(2.6)$ \\
\hline 1 & $1(0.8)$ & $0(0.0)$ & $3(13.0)$ & $1(14.3)$ & $4(2.5)$ & $1(2.6)$ \\
\hline $2-5$ & $8(5.8)$ & $1(3.2)$ & $2(8.7)$ & $3(42.8)$ & $10(6.3)$ & $4(10.5)$ \\
\hline $6-11$ & $11(8.0)$ & $1(3.2)$ & $2(8.7)$ & $1(14.3)$ & $13(8.1)$ & $2(5.4)$ \\
\hline $12-17$ & $20(14.6)$ & $3(9.7)$ & $0(0.0)$ & $0(0.0)$ & $20(12.5)$ & $3(7.9)$ \\
\hline $18-64$ & $94(68.6)$ & $22(71.0)$ & $0(0.0)$ & $0(0.0)$ & $94(58.7)$ & $22(57.9)$ \\
\hline $65-74$ & $0(0.0)$ & $3(9.7)$ & $0(0.0)$ & $1(14.3)$ & $0(0.0)$ & $4(10.5)$ \\
\hline Over 74 & $0(0.0)$ & $1(3.2)$ & $0(0.0)$ & $0(0.0)$ & $0(0.0)$ & $1(2.6)$ \\
\hline \multicolumn{7}{|c|}{ Treatment modality at inclusion } \\
\hline Prophylaxis & $62(45.3)$ & $16(51.6)$ & $8(34.8)$ & $3(42.9)$ & $70(43.8)$ & $19(50.0)$ \\
\hline On demand & $75(54.7)$ & $15(48.4)$ & $15(65.2)$ & $4(57.1)$ & $90(56.2)$ & $19(50.0)$ \\
\hline \multicolumn{7}{|c|}{ Treatment modality at the end of study } \\
\hline Prophylaxis & $96(70.1)$ & $18(58.1)$ & $23(100.0)$ & $4(57.1)$ & $119(74.4)$ & $22(57.9)$ \\
\hline On demand & 41 (29.9) & 13 (41.9) & $0(0.0)$ & $3(42.9)$ & 43 (26.9) & $16(42.1)$ \\
\hline
\end{tabular}

Abbreviations: ED, exposure day; PTP, previously treated patient; PUP, previously untreated patient.

ancluding minimally treated patients with fewer than 50 EDs and 150 EDs. ${ }^{22}$

${ }^{b}$ One PUP received at the very first treatment a different pdFVIII product, before starting treatment with pdFVIII.

${ }^{c}$ One PUP with severe hemophilia A was treated for 24 EDs during the study and was then lost to follow-up.

${ }^{\mathrm{d}}$ Missing for 2 patients at inclusion and 1 patient throughout the study period; presented as patient with severe hemophilia A.

Twenty-four patients were followed up for more than 15 years, of whom 21 were PTPs and 3 (initially) PUPs.

\section{Demographic Data}

All patients were male and almost all were Caucasian, with 4 exceptions: 2 were black, 1 was Asian, and 1 was Arabian. At the time of inclusion in the NIS, patients had a mean age of $25.1 \pm 18.7$ years, with ages ranging from 0 to 80 years. PTPs were aged $28.9 \pm 17.0$ years, ranging from 0 to 80 years, and PUPs were aged $3.5 \pm 11.8$ years (median 1.0 years), ranging from 0 to 65 years (details in -Table 1 ). The oldest PTP turned 88 years old during the study.

\section{Treatment Data}

A total of 213,471,262 international units (IU) of pdFVIII were administered in 130,595 treatments during the study period; of these $70.5 \%$ were given as prophylactic treatment and $29.1 \%$ as bleeding or follow-on treatment.

On average, $31.6 \pm 15.2 \mathrm{IU} / \mathrm{kg}$ body weight (BW) were administered per exposure. Patients received on average $8.3 \pm 5.1$ treatments per month ( - Table 2 ).

\section{Effectiveness}

The ABR was considerably lower for patients who were treated prophylactically (mean ABR of $5.4 \pm 6.3$; median 3.1 ; range 0.0-30.5) compared with those patients treated on demand (mean ABR of $26.1 \pm 19.2$; median 21.9; range 0.0-113.3) for the entire study period. Spontaneous and traumatic bleedings were included in calculating the ABR.
The mean dose of prophylaxis ( $31.5 \pm 15.4 \mathrm{IU} / \mathrm{kg}$ BW; median $28.9 \mathrm{IU} / \mathrm{kg}$ BW; range 9.1-120.4 IU/kg BW; see - Table 2) and the mean frequency per month $(6.4 \pm 5.9$; median 5.7 ; range $0.0-30.0 ; n=156)$ of prophylactic treatments varied substantially between the patients. Overall, considering all patients, the ABR decreased over time, from a median ABR of 20.7 (mean $23.7 \pm 23.6 ; n=90$ ) in the period 1998 to 2002 to 5.2 (mean $13.2 \pm 18.8 ; n=123$ ) in the period 2008 to 2012 and finally to 2.6 (mean $7.2 \pm 10.4 ; n=70$ ) in the period 2013 to 2015. In parallel, the proportion of patients receiving prophylactic treatment increased during the long-term treatment with pdFVIII from 41.1\% (37/90 patients) in 2003 to $52.3 \%(46 / 88)$ in 2008 , to $63.6 \%(42 / 66)$ in 2013 , and finally to $65.7 \%(44 / 67)$ in 2015 . These results were similar for patients with severe and nonsevere hemophilia A. The increasing proportion of prophylaxis during the whole study period can also be seen when comparing the treatment modalities of patients at inclusion $(N=198)$ with their treatment modalities at the end of their study periods (-Table 1). A higher increase of prophylaxis was observed in patients with severe hemophilia A and PUPs at inclusion compared with patients with nonsevere hemophilia A and PTPs at inclusion.

As presented in the interim analysis, ${ }^{9}$ the type of treatment varied considerably between patients treated in Germany or Hungary. These initial country-specific differences in regimens and dosing decreased during the study period.

The joint status was documented for 57 patients from 2010 onwards. Of these patients, 53 had affected joints, of 
Table 2 Treatment and dosing data; annual bleeding rate

\begin{tabular}{|c|c|c|c|}
\hline Mean \pm SD & $N=198^{\mathrm{a}}$ & $n$ (severe) $=160^{\mathrm{a}}$ & $n$ (nonsevere) $=38$ \\
\hline Total doses administered (IU) & $1,089,139 \pm 1,028,721$ & $1,197,545 \pm 1,035,781$ & $691,213 \pm 908,873$ \\
\hline Doses administered per year (IU/y) & $164,965 \pm 123,343$ & $173,159 \pm 122,918$ & $133,951 \pm 123,141$ \\
\hline $\begin{array}{l}\text { Doses administered per year and } \\
\text { body weight }(\mathrm{IU} / \mathrm{kg} / \mathrm{y})\end{array}$ & $3,277 \pm 3,381$ & $3,557 \pm 3,623$ & $2,131 \pm 1,764$ \\
\hline No. of infusions administered per year & $99.9 \pm 61.1$ & $106.5 \pm 62.7$ & $69.7 \pm 44.8$ \\
\hline No. of infusions & $665.9 \pm 580.8$ & $744.6 \pm 593.5$ & $366.7 \pm 415.3$ \\
\hline Percentage of infusions, on-demand (\%) & $34.9 \pm 36.6$ & $33.6 \pm 35.9$ & $41.7 \pm 39.8$ \\
\hline Percentage of infusions, prophylaxis $(\%)^{c}$ & $64.3 \pm 37.3$ & $66.1 \pm 35.8$ & $55.6 \pm 42.7$ \\
\hline Percentage of infusions, surgery (\%) & $0.8 \pm 3.7$ & $0.3 \pm 0.8$ & $2.7 \pm 8.0$ \\
\hline Dose per infusion (IU/kg) & $31.6 \pm 15.2$ & $31.78 \pm 15.7$ & $31.68 \pm 13.0$ \\
\hline On-demand $^{\mathrm{b}}$ & $33.4 \pm 17.4$ & $33.7 \pm 18.5$ & $32.6 \pm 12.4$ \\
\hline Prophylaxis $^{\mathrm{c}}$ & $31.5 \pm 15.4$ & $32.3 \pm 15.8$ & $28.4 \pm 13.3$ \\
\hline Surgery & $60.7 \pm 37.6$ & $62.9 \pm 41.1$ & $51.9 \pm 17.1$ \\
\hline ABR $^{\mathrm{d}}$ during prophylaxis ${ }^{\mathrm{c}}$ (median) & $5.4 \pm 6.3(3.1)$ & $5.8 \pm 6.7(3.3)$ & $3.4 \pm 3.5(2.2)$ \\
\hline $\mathrm{ABR}^{\mathrm{d}}$ during on-demand ${ }^{\mathrm{b}}$ treatment (median) & $26.1 \pm 19.2(21.9)$ & $30.8 \pm 18.4(29.3)$ & $7.9 \pm 7.4(5.6)$ \\
\hline
\end{tabular}

Abbreviations: ABR, annual bleeding rate; ED, exposure day; SD, standard deviation.

aData derived from 40-196 (32-156/8-38) patients as applicable and available.

b“On-demand" means either primary treatment of a bleeding episode or follow-on treatment, if needed, for the same episode.

'Prophylaxis was not predefined and varied in administered dosages and their frequencies.

Including traumatic and spontaneous bleedings.

which 47 patients had an impact on their daily life. Walking impairment and total knee replacement was documented for 24 and four patients, respectively.

Overall, 156 surgical procedures were performed successfully in 79 patients under long-term therapy with pdFVIII; of these 145 were performed in 72 PTPs and 11 in 8 PUPs. Twentynine procedures were successfully performed in 18 patients with nonsevere hemophilia A (of these five were in two PUPs).

Investigators assessed the therapeutic effect of treatment as "successful" for nearly all (99.4\%) treatments.

The majority of both investigators and patients rated the global effectiveness as "very good": mean assessment by investigators was $1.3 \pm 0.4$ (range $1.0-2.5 ; n=162$ ) and by patients $1.4 \pm 0.5$ (range $1.0-3.5 ; n=160$ ).

On average, patients judged their overall satisfaction with their hemophilia A treatment as "good" ( $1.7 \pm 0.5$; range 1.0 to $3.0 ; n=162)$. The physicians on average assessed the subjective condition of 163 patients as "good" ( $1.7 \pm 0.5$; range $1.0-4.0$ ).

The global ease of use was assessed as "good" or "very good" by the majority of both investigators ( $1.4 \pm 0.5$; range 1.0-3.0; $n=162)$ and patients ( $1.5 \pm 0.5$; range $1.0-3.0 ; n=160)$.

\section{Safety and Tolerability}

During the study period (January 1998-December 2015), within 1,418 patient-years, 10 AEs in seven patients were considered pdFVIII-related, resulting in an adverse drug reaction (ADR) rate of $<0.1$ per patient, 7.1 per 1,000 patient-years, and 0.1 per 1,000 administrations.

All ADRs involved FVIII inhibitor formation documented in 7 patients with severe hemophilia A (3 PUPs and 4 PTPs:
"PUP1-3" and "PTP1-4"; see details in - Supplementary Table 2). All seven patients recovered from the 10 ADRs. In two patients (PUP3, PTP4), the inhibitor formation was recorded twice and in PUP3 an increased bleeding tendency was additionally documented.

From January 1998 to December 2015 (inclusive), no pdFVIII-related thrombosis, thromboembolic event, or hypersensitivity reaction and no suspected viral transmission related to pdFVIII was documented.

During the study, no unexpected information on the safety and tolerability of pdFVIII was acquired.

The incidence of all FVIII inhibitor formation in PUPs with severe hemophilia A was 13\% (3/23), and 4\% (1/23) for hightiter FVIII inhibitors. 3,10

One PUP (PUP2) of African ethnicity ${ }^{11,12}$ developed a hightiter $(\geq 5 \mathrm{BU} / \mathrm{mL}$ ) and persistent inhibitor with a peak titer of $320 \mathrm{BU} / \mathrm{mL}$ (ED 6). ${ }^{10}$ After 11 months of ITI (Bonn Protocol) with pdFVIII, inhibitor test results remained negative.

The other two PUPs showed transient and low-titer inhibitors (peak titers of 0.9 and $1.6 \mathrm{BU} / \mathrm{mL}$; ED 16 and ED 27). ${ }^{3,10}$ The first pdFVIII exposure of PUP1/PUP2 was linked with a severe bleeding and surgical procedure requiring concomitant red blood cell transfusion and $\geq 10 / \geq 5$ consecutive days of intensive pdFVIII treatment. ${ }^{11-22}$

PUP3 was first exposed to pdFVIII at an early age (6 months) and suffered form an intron-22 inversion. ${ }^{11,12,23}$ Inhibitor results remained negative in PUP1/PUP3 after a few days/months of three times weekly doses of approximately $50 \mathrm{IU} / \mathrm{kg}$ pdFVIII.

During the study period, overall four PTPs with severe hemophilia A developed inhibitors, thereof three high-titer inhibitors, resulting in frequencies of 3.3 inhibitors and 2.5 
high-titer inhibitors in 1,000 patient-years with severe hemophilia A. ${ }^{3,10}$ Three PTPs developed transient FVIII inhibitors without any change in treatment. All three PTPs had single hightiter inhibitor results $(5-8 \mathrm{BU} / \mathrm{mL})$ that were not confirmed. Consecutive low-titer inhibitor results were documented for only two of these three PTPs. A fourth PTP (PTP3) developed a low-titer and persistent inhibitor. ${ }^{10}$ During follow-up observation after the study period, inhibitor titer did not increase but a high-dose ITI with pdFVIII was initiated. After 1 month and an initial booster to $30 \mathrm{BU} / \mathrm{mL}$ inhibitor, results remained negative (details in - Supplementary Table 2).

For only one patient (PUP3) with inhibitor formation, an increased bleeding tendency was documented (-Supplementary Table 2). No other bleeding within the study was documented in relation to FVIII inhibitor formation. However, for five patients with FVIII inhibitor development (PUP1, PUP2, PTP2, PTP3, and PTP4), severe bleedings with coexisting inflammation, requiring $\geq 3$ up to $\geq 10$ consecutive days of pdFVIII treatment, were identified as a risk factor for inhibitor formation. In addition, two PTPs with inhibitor formation were treated on demand or had been treated on demand in the past. ${ }^{11-13,18-20,24-27}$

Overall, 16 PUPs with severe hemophilia A suffered from a total of 32 severe bleeding episodes requiring peak treatment moments within their first 50 EDs. Two of these patients (PUP1, PUP2) needed treatment with packed erythrocytes concomitantly with pdFVIII. $3,11-13,20,21$

Two further suspected pdFVIII-related nonserious AEs (joint bleeding, hematoma; cause not documented) were documented by the physician for one adolescent patient with severe hemophilia A. Both AEs were assessed by the sponsor as not pdFVIII-related, but rather as symptoms of the underlying hemophilia $\mathrm{A}$ and probably low prophylactic doses (15 IU/kg BW) and their low frequency ( 1-2 per week). Neither the dosage or the frequency of pdFVIII therapy nor the patient's concomitant medication was changed. No FVIII antibody was diagnosed and the therapeutic effectiveness of pdFVIII was judged to be "very good" by the physician.

Overall, tolerability was assessed globally as "very good" or "good" by both investigators (1.2 \pm 0.4 ; range $1.0-2.0$; $n=162)$ and patients $(1.3 \pm 0.4$; range $1.0-2.0 ; n=160)$.

\section{Discussion}

To our knowledge, this is the longest NIS of a single FVIII concentrate conducted so far, investigating real-life effectiveness and safety in clinical daily routine of prophylactic or ondemand treatment of hemophilia $A$ and its influence on patient health. ${ }^{6,28-31}$ Within this unique study, a broad range of patients with severe as well as nonsevere hemophilia A, covering all age groups (postnatal up to 88 years), was investigated.

Within the study period of nearly two decades, pdFVIII was effective and well tolerated, and no pharmacological safety concern was raised. FVIII inhibitor development within the study was mainly transient, with low titers and without clinical relevance, and was manageable.

In addition to the severe form of hemophilia $\mathrm{A}$, all patients with inhibitor formation showed various risk factors for inhibi- tor formation. ${ }^{25,27}$ Several risk factors are known or currently under discussion: these include the regimen and intensity of factor replacement, age at the start of treatment, coexisting inflammation, type of FVIII product, F8 mutation type, ethnicity, family history of inhibitors, and severity of hemophilia A. ${ }^{5,11-14,16-21,25,32-37}$ Inflammatory danger signals, such as recurrent joint bleeding and severe bleeding episodes (including surgical procedures) requiring peak treatment moments, seem to increase the risk of developing mainly transient and low-titer inhibitors without clinical relevance in both PUPs and PTPs treated on demand with pdFVIII. $3,11-14,18-20,24-27,37$

Overall, rates of inhibitor formation in PUPs and PTPs were low, and lower than or similar to those reported for other pdFVIII products, including the comparisons between plasma-derived and recombinant FVIII products. $5,6,11,22,36$ The higher inhibitor incidence observed in the SIPPET study (27\%) for pdFVIII concentrates, in contrast to the overall inhibitor incidence in the present study (13\%), may be explained inter alia by the different ethnic origins of the patients and the different study settings. The SIPPET study was a randomized, controlled trial with defined inhibitor assessments. ${ }^{22,38}$ However, the incidence of inhibitor formation in PUPs with severe hemophilia A in the present study (overall $13.0 \%$; high-titer $4.3 \%$ ) was comparable to the incidence reported for another vWF-containing pdFVIII product (overall 11.1\%; high-titer $8.9 \%$ ) $^{38}$ and lower compared with incidences reported in the EUHASS, ${ }^{39}$ RODIN, and CANAL studies. ${ }^{12,15}$ Considering applied definitions of inhibitors, ${ }^{10}$ for PTPs, inhibitor incidences were similar to those observed in the EUHASS study or reported by Kempton et al ${ }^{40}$ and Xi et al, ${ }^{5}$ but lower than those observed in the United Kingdom $(>5.3)^{6}{ }^{6}$

There were limitations in data acquisition due mainly to the long observational period, especially at the beginning of the study, mostly on account of items documented at the start of the NIS two decades earlier. Therefore, underreporting of AEs, such as those related to bleeding (e.g., pain or causes of [traumatic] bleeding), elective procedures and underlying hemophilia A, related comorbidities (e.g., arthropathy) and their aggravation cannot be ruled out. However, the documentation and reporting of clinically relevant events, e.g., FVIII inhibitor formation or thromboembolic events, are assumed to have been documented completely.

In addition, no especial attention was given to the development of joint status over time, but only the status of affected joints and their impact on daily life was documented from 2010 onwards. ABRs were calculated on the basis of bleedings (for which no definition was prespecified) and were documented in patient diaries, without the requirement that they be medically confirmed.

Notably, in this study "real-life patients"-i.e., including high-risk patients-instead of carefully selected patients were observed.

\section{Conclusions}

This study covered 18 years of observation and documented 1,418 patient-years. Patients with hemophilia A received longterm prophylactic and on-demand therapy with a pdFVIII concentrate containing vWF. The study has demonstrated that 
this treatment was effective, safe, and well tolerated, with a low incidence of inhibitor formation in PTPs and PUPs. ${ }^{5,11,38}$

Novel therapies, including nonfactor therapeutic agents and gene therapy, are currently being established in hemophilia treatment. Their long-term outcome will need to be established. To date, all novel treatments still rely on some FVIII replacement therapy, i.e., in cases of bleeding. Thus, data on efficacy and safety obtained during long-term therapy with pdFVIII reaffirm that there is no unexpected adverse effect on the health of hemophilia A patients.

\section{What is known about this Topic?}

- Collecting real-life safety and effectiveness data during long-term hemophilia A treatment from clinical practice and daily routine to investigate the treatment's influence on the health of patients of all age groups is essential to prove the long-term tolerability of the FVIII concentrates used and to ensure consistency with the outcomes of clinical studies.

- In long-term noninterventional studies "real-life" patients (including high-risk ones) are included, rather than carefully selecting the patient population.

- Development of FVIII inhibitors remains the most serious complication of the therapy with FVIII concentrates in patients with hemophilia A.

\section{What does this Paper Add?}

- Within the 18 years covered by this noninterventional study, investigating patients with severe as well as nonsevere hemophilia A and aged postnatally up to 88 years, therapy with pdFVIII was assessed as being very effective and well tolerated.

- No unexpected adverse effect on the health of patients, no pdFVIII-related thrombosis, thromboembolic event, or hypersensitivity reaction, and no suspected viral transmission related to pdFVIII were documented.

- FVIII inhibitor development was mainly transient, with low titers, without clinical relevance, and comparable to postmarketing data on other pdFVIII concentrates.

Authors' Contributions

L.N. and C.K. contributed with a significant number of patients to this NIS. A.B. and T.B. designed the Biotest NIS. A.B., J.S., T.B., and S.F.K.K. performed the research. P.D. was responsible for data management and provided statistical support. S.F.K.K., A.B., T.B., and J.S. analyzed the data. The main writing was done by S.F.K.K. Analyses were discussed with W.M., C.K., H.R., and L.N.

All authors reviewed and approved the final manuscript.

Funding

This work was funded by Biotest AG. S.F.K.K, A.B., J.S., and T. B. are employees of Biotest AG. W.M. receives grants and personal fees for lectures and consultancy from Biotest, Bayer, Biogen Idec, CSL Behring, LFB, Novo Nordisk, Octa- pharma, Pfizer, Roche, Shire, Sobi, and UniQure. L.N. receives personal fees for lectures, organizing education, and consultancy from Bayer, Biotest, CSL Behring, Novo Nordisk, Octapharma, Pfizer, Roche, Shire, and Sobi. H.R. receives grants, travel expenses, and/or personal fees for lectures and consultancy from Biotest, Bayer, Chugai/Roche, CSL Behring, Novo Nordisk, Pfizer, Sobi, and Takeda. C.K. and his institution received funding or personal fees from Bayer, Biotest, CSL Behring, Gilead, Intersero, Jansen, Novo Nordisk, Pfizer, Roche, Shire, Sobi, and the Federal Ministry of Education and Research and the EU (IMI, FP7).

\section{Acknowledgments}

This study was sponsored by Biotest AG (Dreieich, Germany) and Intersero GmbH (Walluf, Germany). We thank all investigators and study personnel for documenting the patients in the NIS. Physicians involved in the study in Germany were Günter Auerswald (Klinikum Bremen Mitte), Barbara Eifrig (Universitätsklinikum Hamburg), Carmen Escuriola-Ettingshausen and Wolfhart Kreuz (Hämophilie-Zentrum Rhein Main, Mörfelden-Walldorf), Oliver von Falkenhausen (Hausarztzentrum, Groß Zimmern), Susan Halimeh (Gerinnungszentrum Rhein-Ruhr, Duisburg), Christine Heller and Christoph Königs (Klinik für Kinder- und Jugendmedizin, Universitätsklinikum Frankfurt/M), Karim Kentouche (Universitätskinderklinik Jena), Robert Klamroth (Vivantes Klinikum, Berlin), Bernhard Maak (Thüringenklinik Saalfeld), Antje Nimtz-Talaska (Kinderarztpraxis Frankfurt/Oder), Ulrike Nowak-Göttl (Universitätsklinikum Schleswig-Holstein), Christine Schubert (Heliosklinikum Erfurt), Michael Schulze (Arztpraxis Leinefelde), Cornelia Wermes (Werlhof-Institut, Hannover), and Heiner Wolf (Arztpraxis Dresden); those in Hungary were Zoltán Boda and Ágota Schlammadinger (Debreceni Egyetem Klinikai Központ II. Belgyógyászati Klinika), Rita Jager (OVSZ Szombathelyi Területi Vérellátó), Anikó Marosi (Budapesti Gyermek Hemofília Gondozó, Heim Pál Gyermekkórház Madarász Utcai Gyermek Kórháza), Ágnes Nagy (Pécsi Tudomány Egyetem ÁOK Klinikai Központ I.Belgyógyászati Klinika), László Nemes (Magyar Honvédség, Honvédkórház, Országos Hemophilia Központ és Hemostasis Szakrendelés), and Judit Örs (OVSZ Soproni Területi Vérellátó).

\section{References}

1 Miesbach W, O'Mahony B, Key NS, Makris M. How to discuss gene therapy for haemophilia? A patient and physician perspective. Haemophilia 2019;25(04):545-557

2 Weyand AC, Pipe SW. New therapies for hemophilia. Blood 2019; 133(05):389-398

3 van den Berg HM. Epidemiological aspects of inhibitor development redefine the clinical importance of inhibitors. Haemophilia 2014;20(04, Suppl 4):76-79

4 Peyvandi F, Mannucci PM, Palla R, Rosendaal FR. SIPPET: methodology, analysis and generalizability. Haemophilia 2017;23(03):353-361

5 Xi M, Makris M, Marcucci M, Santagostino E, Mannucci PM, Iorio A. Inhibitor development in previously treated hemophilia A patients: a systematic review, meta-analysis, and meta-regression. J Thromb Haemost 2013;11(09):1655-1662 
6 Hay CR, Palmer B, Chalmers E, et al; United Kingdom Haemophilia Centre Doctors' Organisation (UKHCDO). Incidence of factor VIII inhibitors throughout life in severe hemophilia A in the United Kingdom. Blood 2011;117(23):6367-6370

7 van Velzen AS, Eckhardt CL, Peters M, et al. Intensity of factor VIII treatment and the development of inhibitors in non-severe hemophilia A patients: results of the INSIGHT case-control study. J Thromb Haemost 2017;15(07):1422-1429

8 CHMP. Guideline on the clinical investigation of recombinant and human plasma-derived factor VIII products. EMA/CHMP/BPWP/ 144533/2009 rev 2. 2018. Available at: https://www.ema.europa. $\mathrm{eu} / \mathrm{en} /$ documents/scientific-guideline/guideline-clinical-investigation-recombinant-human-plasma-derived-factor-viii-products-revision-2_en.pdf. Accessed September 25, 2019

9 Nemes L, Pollmann H, Becker T. Interim data on long-term efficacy, safety and tolerability of a plasma-derived factor VIII concentrate in 109 patients with severe haemophilia A. Haemophilia 2012;18(04):496-502

10 Blanchette VS, Key NS, Ljung LR, Manco-Johnson MJ, van den Berg HM, Srivastava A; Subcommittee on Factor VIII, Factor IX and Rare Coagulation Disorders of the Scientific and Standardization Committee of the International Society on Thrombosis and Hemostasis. Definitions in hemophilia: communication from the SSC of the ISTH. JThromb Haemost 2014;12(11): 1935-1939

11 Calvez T, Chambost H, d'Oiron R, et al. Analyses of the FranceCoag cohort support differences in immunogenicity among one plasma-derived and two recombinant factor VIII brands in boys with severe hemophilia A. Haematologica 2018;103(01):179-189

12 Gouw SC, van den Berg HM, Fischer K, et al; PedNet and Research of Determinants of INhibitor development (RODIN) Study Group. Intensity of factor VIII treatment and inhibitor development in children with severe hemophilia A: the RODIN study. Blood 2013; 121(20):4046-4055

13 Gouw SC, van den Berg HM, le Cessie S, van der Bom JG. Treatment characteristics and the risk of inhibitor development: a multicenter cohort study among previously untreated patients with severe hemophilia A. JThromb Haemost 2007;5(07):1383-1390

14 Eckhardt CL, van der Bom JG, van der Naald M, Peters M, Kamphuisen PW, Fijnvandraat K. Surgery and inhibitor development in hemophilia A: a systematic review. JThromb Haemost 2011;9(10):1948-1958

15 Gouw SC, van der Bom JG, Marijke van den Berg H. Treatmentrelated risk factors of inhibitor development in previously untreated patients with hemophilia A: the CANAL cohort study. Blood 2007;109(11):4648-4654

16 Sharathkumar A, Lillicrap D, Blanchette VS, et al. Intensive exposure to factor VIII is a risk factor for inhibitor development in mild hemophilia A. JThromb Haemost 2003;1(06):1228-1236

17 ter Avest PC, Fischer K, Mancuso ME, et al; CANAL Study Group. Risk stratification for inhibitor development at first treatment for severe hemophilia A: a tool for clinical practice. J Thromb Haemost 2008;6 (12):2048-2054

18 Kruse-Jarres R. Inhibitors: our greatest challenge. Can we minimize the incidence? Haemophilia 2013;19(01, Suppl 1):2-7

19 Matzinger P. The danger model: a renewed sense of self. Science 2002;296(5566):301-305

20 Santagostino E, Mancuso ME, Rocino A, et al. Environmental risk factors for inhibitor development in children with haemophilia A: a case-control study. Br J Haematol 2005;130(03):422-427

21 Lorenzo JI, López A, Altisent C, Aznar JA. Incidence of factor VIII inhibitors in severe haemophilia: the importance of patient age. Br J Haematol 2001;113(03):600-603

22 Peyvandi F, Mannucci PM, Garagiola I, et al. A randomized trial of factor VIII and neutralizing antibodies in hemophilia A. N Engl J Med 2016;374(21):2054-2064
23 Rosendaal FR, Palla R, Garagiola I, Mannucci PM, Peyvandi F, SIPPET Study Group. Genetic risk stratification to reduce inhibitor development in the early treatment of hemophilia A: a SIPPET analysis. Blood 2017;130(15):1757-1759

24 Astermark J, Lacroix-Desmazes S, Reding MT. Inhibitor development. Haemophilia 2008;14(03, Suppl 3):36-42

25 Gomez K, Klamroth R, Mahlangu J, Mancuso ME, Mingot ME, Ozelo MC. Key issues in inhibitor management in patients with haemophilia. Blood Transfus 2014;12(01, Suppl 1):s319-s329

26 Ragni MV, Ojeifo O, Feng J, et al; Hemophilia Inhibitor Study. Risk factors for inhibitor formation in haemophilia: a prevalent casecontrol study. Haemophilia 2009;15(05):1074-1082

27 Collins PW, Chalmers E, Hart DP, et al. Diagnosis and treatment of factor VIII and IX inhibitors in congenital haemophilia: (4th edition). UK Haemophilia Centre Doctors Organization. Br J Haematol 2013;160(02):153-170

28 Klamroth R, Holzhauer S, Zimmermann R, Heller C, Kurnik K, Beriate ${ }^{\circledR}$ Pharmacovigilance Group. Beriate ${ }^{\circledR} \quad P$ in the treatment of patients with haemophilia A: results of a long-term pharmacovigilance study. Thromb Res 2014;134(Suppl 1):S16-S21

29 Manco-Johnson MJ, Kempton CL, Reding MT, et al. Randomized, controlled, parallel-group trial of routine prophylaxis vs. ondemand treatment with sucrose-formulated recombinant factor VIII in adults with severe hemophilia A (SPINART). JThromb Haemost 2013;11(06):1119-1127

30 Li C, Zhang X, Zhao Y, et al. Long-term efficacy and safety of prophylaxis with recombinant factor VIII in Chinese pediatric patients with hemophilia A: a multi-center, retrospective, noninterventional, phase IV (ReCARE) study. Curr Med Res Opin 2017;33(07):1223-1230

31 Zhao Y, Xiao J, Yang R, et al. Efficacy of standard prophylaxis versus on-demand treatment with bayer's sucrose-formulated recombinant FVIII (rFVIII-FS) in Chinese children with severe hemophilia A. Pediatr Hematol Oncol 2017;34(03):138-148

32 European Medicines Agency. Report of expert meeting on factor VIII products and inhibitor development 2007. Available at: https:// www.ema.europa.eu/en/documents/report/report-expert-meetingfactor-viii-products-inhibitor-development_en.pdf. Accessed September 25, 2019

33 Franchini M, Frattini F, Crestani S, Bonfanti C. Alloantibodies in previously untreated hemophilia A patients: the role of environmental factors. Hematology 2013;18(04):183-190

34 Schwarz J, Astermark J, Menius ED, et al; Hemophilia Inhibitor Genetics Study Combined Cohort. F8 haplotype and inhibitor risk: results from the Hemophilia Inhibitor Genetics Study (HIGS) Combined Cohort. Haemophilia 2013;19(01):113-118

35 Marcucci M, Mancuso ME, Santagostino E, et al. Type and intensity of FVIII exposure on inhibitor development in PUPs with haemophilia A. A patient-level meta-analysis. Thromb Haemost 2015; 113(05):958-967

36 Lebreton A, Castet S, Falaise C, Rugeri L, Schved JF, Wibaut B. After the SIPPET study: position paper of the CoMETH, the French society of haemophilia. Haemophilia 2018;24(02):e55-e57

37 van den Berg HM, Gouw SC, van der Bom JG. Factor VIII products and inhibitors in severe hemophilia A. N Engl J Med 2013;368(15):1457

38 Klukowska A, Komrska V, Vdovin V, et al. Low incidence of factor VIII inhibitors in previously untreated patients with severe haemophilia A treated with octanate ${ }^{\circledR}$ : Final report from a prospective study. Haemophilia 2018;24(02):221-228

39 Fischer K, Lassila R, Peyvandi F, et al; EUHASS participants. Inhibitor development in haemophilia according to concentrate. Four-year results from the European HAemophilia Safety Surveillance (EUHASS) project. Thromb Haemost 2015;113(05):968-975

40 Kempton CL, Soucie JM, Abshire TC. Incidence of inhibitors in a cohort of 838 males with hemophilia A previously treated with factor VIII concentrates. JThromb Haemost 2006;4(12):2576-2581 